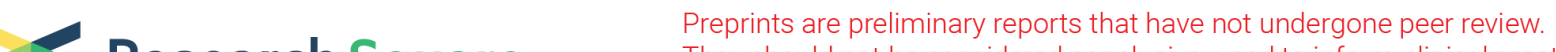 Research Square
They should not be considered conclusive, used to inform clinical practice,
or refernced by the media as validated information.
}

\section{The Impact of Fluid Resuscitation on Hemodynamic of Hemorrhagic Shock: An Animal Model Experimental Study}

\section{Antonius Hocky Pudjiadi ( $\sim$ ahpudjiadi@gmail.com )}

Faculty of Medicine, Universitas Indonesia - Cipto Mangunkusumo Hospital https://orcid.org/00000002-5675-195X

\section{Agus Firmansyah}

Department of Child Health, Faculty of Medicine Universitas Indonesia, Cipto Mangunkusumo Hospital, Jakarta.

\section{Gunanti Soeyono}

Faculty of Veterinary Medicine, Bogor Agricultural University, Bogor.

\section{Saptawati Bardosono}

Postgraduate Program Study, Program in Nutrition, Faculty of Medicine Universitas Indonesia

\section{Sri Widia Jusman}

Department of Biochemistry and Biology Molecular, Faculty of Medicine Universitas Indonesia

\section{Minarma Siagian}

Department of Physiology Faculty of Medicine Universitas Indonesia

\section{Munar Lubis}

Department of Child Health, North Sumatera University Hospital, Faculty of Medicine North Sumatera

\section{Research article}

Keywords: Hemorrhagic shock, fluid resuscitation, Cl, MAP, SVRI, D02, ANP, Syndecan-1, ELWI

Posted Date: January 13th, 2020

DOl: https://doi.org/10.21203/rs.2.20679/v1

License: (c) (i) This work is licensed under a Creative Commons Attribution 4.0 International License. Read Full License 


\section{Abstract}

Background: To investigate the effect of fluid resuscitation on glycocalyx shedding, and extravascular lung water index (ELWI), mean arterial pressure (MAP) and oxygen delivery $\left(\mathrm{DO}_{2}\right)$ changes.

Methods: Male domestic piglets (Sus scrofa) 6-10 weeks old anesthetized and bled until mean arterial pressure drop to $20 \%$ of baseline and resuscitated with normal saline as much as blood drowned, followed with $40 \mathrm{~mL} / \mathrm{kg}$ of normal saline after 30 minutes. Cardiac index $(\mathrm{Cl})$, ELWI, systemic vascular resistance index (SVRI), MAP, atrial natriuretic peptide (ANP) and syndecan-1 were measured before and after each fluid resuscitations.

Results: Serum ANP was increased after normal volume fluid resuscitation $(p=0.043)$ and return its baseline value after hypervolemia fluid resuscitation. Serum Syndecan-1 levels did not increase. A small increase in ELWI only found 60 minutes after fluid resuscitation $(p=0.021)$. SVRI undergo a gradual decrease, until the lowest value at hypervolemia volume resuscitation. There was no difference between the MAP of the two groups $(p=0.105)$. Hemoglobin concentration significantly decreased from normal to hypervolemia volume resuscitation $(p=0.009)$. Oxygen delivery in hypervolemia resuscitation is higher than in normal volume resuscitation $(p=0.012)$, due to a significant increase in $\mathrm{Cl}$ at hypervolemia volume resuscitation $(p<0.001)$.

Conclusions: Hypervolemia fluid resuscitation in the animal hemorrhage model is not induced glycocalyx shedding. Small increase ELWI was found in 60 minutes after fluid resuscitation. $\mathrm{DO}_{2}$ is maintained by increasing $\mathrm{Cl}$ in spite of decreasing hemoglobin level due to hemodilution. Increasing $\mathrm{Cl}$ is balanced by reducing SVRI to sustain stable MAP.

\section{Background}

Most of the pediatric guidelines recommend liberal fluid resuscitation. However, excess fluid resuscitation may lead to complications including hemodilution, impairment of oxygen delivery, and hypothermia.[i] [ii] Fluid resuscitation increases the hydrostatic pressures of the pulmonary circulation and stimulates the release of atrial natriuretic peptides (ANP) due to acute stretching of the walls of the atria.[iii] [iv],[v] These physiological changes may lead to shedding of the endothelial glycocalyx, elevated extravascular lung water index (ELWI), and increased mortality.[vi]][vii]

The endothelial glycocalyx plays an important role in regulating fluid movement. A study performed in dengue-infected patients showed that shedding of vascular endothelial glycocalyx, as indicated by elevated levels of syndecan-1 and chondroitin sulfate, is strongly associated with severe plasma leakage. [viii] Chappell and colleagues reported that $20 \mathrm{~mL} / \mathrm{kg}$ volume loading with crystalloid increased the serum concentration of ANP, hyaluronan, and syndecan-1.[ix] ANP has inherent vasodilating properties via the cGMP pathway. [x] 
The goal of fluid resuscitation is to increase the patient's preload and subsequently the stroke volume. According to the Frank-Starling law, increases in preload will produce an increase in stroke volume. However, this relationship only continues up until the Frank-Starling curve reaches a plateau, after which no further increase in stroke volume occurs. This concept is based on Sarnoff and Berglund's classic experiments in dogs with an intact circulation system.[xi]

The use of piglets (Sus scrofa) have been validated as a model for hemodynamic measurement using $\mathrm{PiCCO} /$ thermodilution in many studies. [xii] Sus scrofa has been used in various research to investigate physiological and treatment responses to hemorrhagic shock with reliable reproducibility. Furthermore, compared to other hemorrhagic shock models (such as rodents), swine model has comparable resting heart rate to those of humans $(60-100 \mathrm{bpm})$.[xiii]

Understanding the mechanism of vascular leakage and hemodynamic changes during fluid resuscitation is essential to develop safe clinical guidelines for fluid resuscitation in children. In this experimental animal study, we investigated the effects of normal volume, i.e. euvolemic fluid resuscitation, and hypervolemic fluid resuscitation on serum ANP and syndecan-1 levels, ELWI, Cl, SVRI, MAP, Hb, and DO 2 .

\section{Methods}

\section{Ethics}

Eleven male domestic pigs (Sus scrofa) was bred by and obtained from the Faculty of Veterinary Medicine, Bogor Agricultural Institute. The animals were treated according to the standard management of the Faculty of Veterinary Medicine, Bogor Agricultural University. Prior to the experiment, both written informed consent and ethical approval were obtained from the Animal Ethics Commission of the Faculty of Veterinary Medicine, Bogor Agricultural University (055/KEH/SKE/III/2017). The animal was acclimatized for 15 days, in which they were given antibiotics oxytetracycline (10 mg/kgBW) via intramuscular route, and anti-helminth (oxfendazole) bolus mixed with their food. The experiment was conducted in the Laboratory Animal Management Unit where the animals were fed commercially available food twice daily with free access to water, and were placed in a cage that was cleaned twice daily.

As there was no need to sacrifice the animals, following the experiment and fluid resuscitation, the animals were returned to the institution and treated by veterinarian. The animals were stabilized and given analgesia and antibiotics for one week course. No animals died during the course of the study.

\section{Study Design}

This was a two-phase fluid resuscitation animal study performed at the Experimental Surgery and Radiology Laboratory, Faculty of Veterinary Medicine, Bogor Agricultural University. Eleven healthy male domestic piglets (Sus scrofa), age 6-10 weeks old were anesthetized with Ketamine and Xylazine and supported by volume control mechanical ventilation, adjusted to blood gas. We infused $3 \mathrm{~mL} / \mathrm{kg} / \mathrm{hour}$ of 
$0.9 \%$ normal saline as maintenance fluid. Environmental temperature was maintained with a thermal blanket. After one hour of stabilization, hemodynamic parameters were measured, and a blood sample taken for laboratory assay of plasma levels. Following baseline data collection, we induced pressure targeted shock via venous blood drawing until the MAP was reduced by $20 \%$ to $80 \%$ of the initial MAP. Hemodynamic parameters were recorded. Following 30 minutes of shock, we performed fluid resuscitation in two phases.[i]

In phase 1, a bolus of normal saline equal in volume to the blood loss needed to induce shock was administered. Phase 2 was performed 30 minutes later, with $40 \mathrm{~mL} / \mathrm{kg}$ of saline given as a bolus, to stimulate hypervolemic resusictation. Hemodynamic parameters were measured three times, at 3 minute intervals, for each stage of fluid resuscitation, and at 30 minutes and 1 hour after the last fluid administration. The numerical means of each data set were used for the statistical analysis.

\section{Hemodynamic Measurements}

Cl, ELWI, SVRI, and MAP were measured using a PiCCO Plus v4.12 System (Pulsion Medical Systems AG, Munich, Germany). Body surface area formula was $734^{*}$ (body weight in $\left.\mathrm{kg}\right)^{0.656}$. [ii] Cardiac output was calibrated for each measurement using the thermodilution method, with a $10 \mathrm{~mL}$ bolus of cold normal saline. ANP and syndecan-1 were measured in duplicate using commercially available enzyme-linked immunosorbent assay (ELISA) for Sus scrofa, performed according to the manufacturer's recommendations (Cloud-Clone Corp., USA), Hb samples were measured in duplicate using an Erma PCE 210 hematology analyzer (Diamond Diagnostic, USA).

\section{Statistical Analysis}

Sample size calculation was performed using Federer's formula.[iii] As we used a two-phase model, euvolemic vs hypervolemic fluid resuscitation in one single study group, the minimum sample size required was 9 animals. To allow for errors in data collection and subject dropout, we studied 11 piglets.

Normally distributed data are presented as means and standard deviation values, whilst nonparametric data are presented as medians and ranges. ANP, syndecan-1, Cl, SVRI, MAP, Hb, and DO2 were normally distributed, but ELWI at baseline, after hypervolemic fluid resuscitation, and at 30 and 60 minutes after hypervolemic resuscitation were not normally distributed. A statistical hypothesis test with paired t-test was used for normally distributed data and Wilcoxon signed-rank test for nonparametric data. Pearson correlation coefficient was used to measure the strength of linear association between ANP and SVRI. The statistical analysis was performed using SPSS Version 20.0.

\section{Results}

The baseline data and characteristics of all subjects are shown in Table 1. Mean blood drawn to produce a $20 \%$ fall in MAP was $101 \pm 56 \mathrm{~mL}$. The average time required for euvolemic fluid resuscitation was $2 \pm$ 1 minutes, and for hypervolemic resuscitation, 9 (7-24) minutes. Changes in hemodynamic profiles during 
the study are shown in Table 2 . The highest $\mathrm{Cl}, \mathrm{MAP}$, and $\mathrm{DO}_{2}$ were recorded following hypervolemic resuscitation, whilst SVRI was lowest at this time. ELWI increased gradually until 1 hour after hypervolemic resuscitation.

Figure 1 shows that ANP increased significantly from $85.20 \pm 40.86 \mathrm{ng} / \mathrm{L}$ at baseline to $106.42 \pm 33.71$ $\mathrm{ng} / \mathrm{L}$ following euvolemic resuscitation $(\mathrm{p}=0.043)$. Serum ANP decreased to $82.60 \pm 41.21 \mathrm{ng} / \mathrm{L}$ and $83.55 \pm 46.09 \mathrm{ng} / \mathrm{L}$ respectively immediately following hypervolemic resuscitation and 30 minutes after hypervolemic resuscitation. Serum syndecan-1 levels did not increase during this study.

Figure 2 shows the data for ELWI at baseline. There was no significant difference between ELWI at euvolemia and baseline value ( $p=0.722)$, nor following hypervolemic resuscitation and baseline $(p=$ 0.398), but there was a significant difference between baseline value and 60 minutes following hypervolemic resuscitation $(p=0.021)$. SVRI shows a gradual decrease, with nadir values after hypervolemic resuscitation. There was no correlation between serum ANP changes and SVRI $(r=0.106 ; p=$ 0.281). There was no difference between the MAP between euvolemic and hypervolemic resuscitation at any point in the study $(p=0.105)$. Hemoglobin concentration decreased significantly from $9.32 \pm 0.86$ $\mathrm{g} / \mathrm{dL}$ after euvolemic resuscitation to $8.39 \pm 0.79 \mathrm{~g} / \mathrm{dL}$ following hypervolemic resuscitation $(\mathrm{p}=0.009)$. Oxygen delivery following hypervolemic resuscitation at $2281 \pm 525 \mathrm{ml} /$ minute was significantly higher than after normovolemic resuscitation, $2028 \pm 409 \mathrm{ml} /$ minute $(p=0.012)$, as seen in Figure 4.

\section{Discussion}

This study showed that ANP levels increase, immediately after normovolemic resuscitation. The ANP levels then decrease to near baseline levels before shock was induced. This result is similar that found by Ozer et al.[i] They showed that the factor limiting increased ANP secretion was the intact pericardium. Maximal increase in ANP secretion was significantly higher when the pericardium was removed. Increasing ANP was not found in the study of Chappell et al. where fluid infusion to maintain euvolemia was carried out simultaneously with blood removal resulting in euvolemic hemodilution. ${ }^{9}$ We believe that the rapid volume expansion in this study induces ANP secretion. It should also be noted that Chappell et al. expressed their serum ANP levels in $\mathrm{ng} / \mathrm{L}$ of albumin which corrected for the hemodilution factor.

The limited degree and short duration of increased ANP did not cause any glycocalyx shedding. However extravascular lung water was increased by $0.93 \mathrm{~mL} / \mathrm{kg}$. A study in acute lung injury induced in pigs showed that the ELWI was increased from $6.3 \mathrm{~mL} / \mathrm{kg}$ at baseline, to $9.4 \mathrm{~mL} / \mathrm{kg} 3$ hours after fluid resuscitation.[ii] Zhao and coworkers showed in adult ARDS patients, ELWI in their survival group was $13.0 \pm 3.6 \mathrm{~mL} / \mathrm{kg}$ and in non-survivors $19.0 \pm 3.0 \mathrm{~mL} / \mathrm{kg}$.[iii] Lemson and colleagues reported ELWI was significantly higher in children and negatively correlated with age.[iv] In children, there is no correlation between ELWI and the number of ventilator days, the severity of illness and markers of oxygenation. ${ }^{20}$ In contrast to Marik's prediction [v], with $40 \mathrm{~mL} / \mathrm{kg}$ fluid bolus, our study does not show significant fluid extravasation. Species differences might play a role here, but no glycocalyx shedding must be taken in to 
consideration. None of the animals in this study died or were dependent on mechanical ventilation following the experiment.

Apart from the increasing permeability of the vascular endothelial barrier, factors that govern the amount of extravascular lung water are pulmonary vascular pressure, oncotic pressure, and the efficiency of the lymphatic drainage systems. A high ANP level can inhibit lymphatic drainage [vi] [vii] and induce glycocalyx shedding. 6 Since glycocalyx shedding did not happen, ischemia-reperfusion might be the cause of increased vascular permeability. Ischemia-reperfusion can induce downregulation and expression of the tight junction protein, occludin.[viii]

Although there was no correlation between ANP changes and SVRI, we found SVRI decreases gradually after fluid resuscitation. A decrease in arterial elastance and SVRI after fluid resuscitation has been reported in septic patients by Monge Garcia and colleagues.[ix] SVRI reduction can be induced by parasympathetic activity $[\mathrm{x}]$ to compensate for the increase in cardiac output. Figure 3 shows the increased $\mathrm{Cl}$ was balanced by the reduction of SVRI, such that the MAP remains stable. Our results show that the MAP at euvolemia and after hypervolemic resuscitation remain the same. Since increasing $\mathrm{Cl}$ will be balanced by decreasing SVRI, a decision to use fluid for increasing MAP must be considered with the risk of increasing ELWI, especially when glycocalyx shedding is occurring. In humans, Glassford and colleagues showed that in sepsis, fluid responders showed a transient increase in MAP of just $9.5 \mathrm{mmHg}$ (7-15.2 mmHg) whilst in the non-responder group MAP increased by $4.8 \mathrm{mmHg}(1-13 \mathrm{mmHg})$.[xi] This finding adds to the view that fluid expansion has a limited role compared to the use of vasoactive medication in patients where MAP increase is required.

Guyton and Lindsey showed that partial constriction of the aorta increased the left atrial pressure in dogs and lead to accumulation of lung edema.[xii] In contrast, decreasing SVRI which results in "forward flow" with increasing $\mathrm{Cl}$ could be a mechanism which opposes the development of excessive ELWI by reducing pulmonary hydrostatic pressure.

Fluid resuscitation increases stroke volume which helps maintain blood pressure. However, fluid resuscitation also dilutes the hemoglobin concentration in the blood, potentially leading to a decrease in $\mathrm{DO}_{2}$. Adequate $\mathrm{DO}_{2}$ is essential for ensuring patient wellbeing. In this study, hemoglobin concentration was significantly lower after hypervolemic resuscitation, but $\mathrm{DO}_{2}$ was higher than after euvolemic resuscitation. Figure 4 shows the role of $\mathrm{Cl}$ in increasing $\mathrm{DO}_{2}$ after hypervolemic resuscitation. In those situations where $\mathrm{Cl}$ cannot increase further, hypervolemic resuscitation should be carefully considered. Despite afterload reduction by decreasing SVRI, there may not be sufficient cardiac reserve to generate an increased $\mathrm{Cl}$.

\section{Conclusions}

Hypervolemic fluid resuscitation in our animal hemorrhage model does not induce glycocalyx shedding. $\mathrm{DO}_{2}$ is maintained by increasing $\mathrm{CO}$ in spite of decreasing hemoglobin level due to hemodilution. 
Increasing $\mathrm{CO}$ is balanced by decreasing SVR to sustain stable MAP. SVRI reduction could be a protective mechanism for a patient with limited cardiac reserve that may support the cardiac output and restrain extravascular lung water. To achieve optimal results with fluid resuscitation, all of these parameters should be monitored. Further studies looking at the interrelationship between fluid resuscitation and $\mathrm{DO}_{2}$ in critically ill children are needed to identify those patients who may benefit from fluid resuscitation and those who could be harmed.

\section{Abbreviations}

ANP Atrial natriuretic peptide

ARDS Acute respiratory distress syndrome

cGMP Cyclic guanosine monophosphate

$\mathrm{Cl} \quad$ Cardiac index

CO Cardiac output

CRRT Continuous renal replacement therapy

$\mathrm{DO}_{2} \quad$ Oxygen delivery

ELISA Enzyme-linked immunosorbent assay

ELWI Extravascular lung water index

$\mathrm{Hb} \quad$ Hemoglobin

MAP Mean arterial pressure

Picco Pulse Contour Cardiac Output

SVR Systemic vascular resistance

SVRI Systemic vascular resistance index

SPSS Statistical Package for the Social Sciences

\section{Declarations}

\section{Ethics approval and consent to participate}

This study obtained ethical approval from Animal Ethical Committee of Faculty of Veterinary Medicine, Bogor Agricultural University, Bogor, with ethical approval number 055/KEH/SKE/III/2017. 


\section{Consent for publication}

Not applicable

\section{Availability of data and materials}

The datasets used and/or analysed during the current study are available from the corresponding author on reasonable request.

\section{Competing interests}

The authors declare that they have no competing interests.

\section{Funding}

No external funding was received for this study. The study and collection, analysis and interpretation of data were self-funded by the authors.

\section{Authors' contributions}

AHP designing, conducting, analyzing the study and writing the manuscript. AF designing the study, overviewing the discussion. GS animal lab coordinator, conducting and reviewing animal protocol, SB designing and reviewing study methodology, SW designing and analyzing study biomarkers, MS Reviewing discussion regarding animal physiology response, ML designing the study and reviewing discussion regarding critical care. All authors have read and approved the manuscript.

\section{Acknowledgments}

Special thanks to Dr. Dwi Utari Rahmiati, and Dr. Sri Murtini, for their assistance in coordinating the animal preparation and laboratory tests. We are also grateful to the Faculty of Veterinary Medicine, Bogor Agricultural University staffs and students for helping the preparation and data collecting.

\section{References}

1. Sihler KC, Napolitano LM. Complications of massive transfusion. Chest. 2010;137(1):209-20.

2. Perel A. latrogenic hemodilution: a possible cause for avoidable blood transfusions? Crit Care. 2017;21(1):291.

3. McGrath MF, de Bold AJ. Determinants of natriuretic peptide gene expression. Peptides. 2005;26(6):933-43.

4. de Bold AJ, Bruneau BG, Kuroski de Bold ML. Mechanical and neuroendocrine regulation of the endocrine heart. Cardiovasc Res. 1996;31(1):7-18.

5. Temsah R, Nemer M. GATA factors and transcriptional regulation of cardiac natriuretic peptide genes. Regul Pept. 2005;128(3):177-85. 
6. Bruegger D, Jacob M, Rehm M, Loetsch M, Welsch U, Conzen P, et al. Atrial natriuretic peptide induces shedding of endothelial glycocalyx in coronary vascular bed of guinea pig hearts. Am J Physiol Heart Circ Physiol. 2005;289(5):H1993-9.

7. Marik P, Bellomo R. A rational approach to fluid therapy in sepsis. British journal of anaesthesia. 2016;116(3):339-49.

8. Suwarto S, Sasmono RT, Sinto R, Ibrahim E, Suryamin M. Association of Endothelial Glycocalyx and Tight and Adherens Junctions With Severity of Plasma Leakage in Dengue Infection. J Infect Dis. 2017;215(6):992-9.

9. Chappell D, Bruegger D, Potzel J, Jacob M, Brettner F, Vogeser M, et al. Hypervolemia increases release of atrial natriuretic peptide and shedding of the endothelial glycocalyx. Crit Care. 2014;18(5):538.

10. Landry DW, Oliver JA. The pathogenesis of vasodilatory shock. N Engl J Med. 2001;345(8):588-95.

11. Sarnoff SJ, Berglund E. Ventricular function. I. Starling's law of the heart studied by means of simultaneous right and left ventricular function curves in the dog. Circulation. 1954;9(5):706-18.

12. Renner J, Meybohm P, Gruenewald M, Steinfath M, Scholz J, Boening A, et al. Global end-diastolic volume during different loading conditions in a pediatric animal model. Anesth Analg. 2007;105(5):1243-9.

13. Xanthos T, Bassiakou E, Koudouna E, Tsirikos-Karapanos N, Lelovas P, Papadimitriou D, et al. Baseline hemodynamics in anesthetized landrace-large white swine: reference values for research in cardiac arrest and cardiopulmonary resuscitation models. J Am Assoc Lab Anim Sci. 2007;46(5):215.

14. Soedjono G, Harlina E, Pudjiadi AH, Purba MS, Widodo SJ. Evaluation of ventilator on lung profile of piglets (Sus scrofa) in hypovolemic shock treated with hypervolemic crystalloid resuscitation. Vet World. 2019;12(4):565-71.

15. Swindle MM, Makin A, Herron AJ, Clubb FJ, Jr., Frazier KS. Swine as models in biomedical research and toxicology testing. Vet Pathol. 2012;49(2):344-56.

16. Federer WT. Randomization and sample size in experimentation. Food and Drug Administration Statistics Seminar; September 19, 1966.; Washington, D. C.1966.

17. Ozer M, Hall C, Bergersen BM. The pericardium acts as a restricting factor on the release of ANF (198) and ANF (99-126) after volume loading in pigs. Int J Cardiol. 1994;45(2):97-102.

18. Nirmalan M, Niranjan M, Willard T, Edwards JD, Little RA, Dark PM. Estimation of errors in determining intrathoracic blood volume using thermal dilution in pigs with acute lung injury and haemorrhage. Br J Anaesth. 2004;93(4):546-51.

19. Zhao Z, Jiang L, Xi X, Jiang Q, Zhu B, Wang M, et al. Prognostic value of extravascular lung water assessed with lung ultrasound score by chest sonography in patients with acute respiratory distress syndrome. BMC Pulm Med. 2015;15:98.

20. Lemson J, van Die LE, Hemelaar AE, van der Hoeven JG. Extravascular lung water index measurement in critically ill children does not correlate with a chest $x$-ray score of pulmonary edema. 
Crit Care. 2010;14(3):R105.

21. Marik PE. Fluid therapy in 2015 and beyond: the mini-fluid challenge and mini-fluid bolus approach. Br J Anaesth. 2015;115(3):347-9.

22. Lobov GI, Pan'kova MN. Atrial Natriuretic Peptide Inhibits Spontaneous Contractile Activity of Lymph Nodes. Bull Exp Biol Med. 2016;161(2):221-3.

23. Ohhashi T, Watanabe N, Kawai Y. Effects of atrial natriuretic peptide on isolated bovine mesenteric lymph vessels. Am J Physiol. 1990;259(1 Pt 2):H42-7.

24. Krizbai IA, Bauer H, Bresgen N, Eckl PM, Farkas A, Szatmari E, et al. Effect of oxidative stress on the junctional proteins of cultured cerebral endothelial cells. Cell Mol Neurobiol. 2005;25(1):129-39.

25. Monge Garcia MI, Guijo Gonzalez P, Gracia Romero M, Gil Cano A, Oscier C, Rhodes A, et al. Effects of fluid administration on arterial load in septic shock patients. Intensive Care Med. 2015;41(7):124755.

26. Lanfranchi PA, Somers VK. Arterial baroreflex function and cardiovascular variability: interactions and implications. Am J Physiol Regul Integr Comp Physiol. 2002;283(4):R815-26.

27. Glassford NJ, Eastwood GM, Bellomo R. Physiological changes after fluid bolus therapy in sepsis: a systematic review of contemporary data. Crit Care. 2014;18(6):696.

28. Guyton AC, Lindsey AW. Effect of elevated left atrial pressure and decreased plasma protein concentration on the development of pulmonary edema. Circ Res. 1959;7(4):649-57.

\section{Tables}

Table 1. Subject Characteristics and Baseline Data.

\begin{tabular}{lll}
\hline & $\mathrm{n}$ & \\
\hline Weight $(\mathrm{kg})$ & 11 & $14.7 \pm 1.3$ \\
BSA $\left(\mathrm{m}^{2}\right)$ & 11 & $0.53 \pm 0.02$ \\
MAP (mmHg) & 11 & $102.6 \pm 14.4$ \\
Blood volume drawn (mL) & 11 & $101 \pm 56$ \\
Time to shock (minutes) & 11 & $8 \pm 4.7$ \\
Normal volume resuscitation time (minutes) & 11 & $2 \pm 1$ \\
Hypervolemia resuscitation time (minutes) & 11 & $9(7-24)$ \\
\hline
\end{tabular}

Values are given as mean \pm SD or median (range). BSA: body surface area; MAP: mean arterial pressure 
Table 2. Changes in Hemodynamics Profiles

\begin{tabular}{lllllll}
\hline & Baseline & Shock & Normal $^{*}$ & Hyper $^{\#}$ & $30 \mathrm{~min}^{\mathrm{Y}}$ & $60 \mathrm{~min}^{\mathrm{i}}$ \\
\hline $\mathrm{SVI}$ & 44.3 & 33.5 & 42.4 & 53.6 & 42.8 & 43.2 \\
$\left(\mathrm{~mL} / \mathrm{m}^{2}\right)$ & \pm 14.3 & \pm 10.0 & \pm 11.1 & \pm 12.3 & \pm 12.9 & \pm 14.9 \\
$\mathrm{CI}$ & $4.0 \pm 1.2$ & $3.2 \pm 0.8$ & $3.8 \pm 0.7$ & $4.7 \pm 0.9$ & $3.9 \pm 0.8$ & $3.5 \pm 0.6$ \\
$\left(\mathrm{l} / \mathrm{min} / \mathrm{m}^{2}\right)$ & & & & & & \\
$\mathrm{SVRI}$ & 10831.0 & 9991.3 & 9034.5 & 8416.1 & 9705 & 8941.1 \\
$\left(\mathrm{dyn} * \mathrm{sec} / \mathrm{cm}^{5} / \mathrm{m}^{2}\right)$ & \pm 3700.8 & \pm 2895.3 & \pm 2634.8 & \pm 1945.3 & \pm 3106.3 & \pm 5561.5 \\
$\mathrm{MAP}$ & $102.6 \pm 14.4$ & $82.3 \pm 8.7$ & $91.5 \pm 13.0$ & $94.6 \pm 9.1$ & $86.6 \pm 6.7$ & $91.6 \pm 9.8$ \\
$(\mathrm{mmHg})$ & & & & & & \\
$\mathrm{DO}$ & & 14.59 & 20.29 & 22.81 & 20.21 & $\mathrm{Not}$ Measured \\
$(\mathrm{mL} / \mathrm{min})$ & \pm 8.65 & \pm 3.54 & \pm 4.1 & \pm 5.26 & \pm 4.67 & \\
$\mathrm{ELWI}$ & $16.5 \pm 8.2$ & $16.5 \pm 7.8$ & $16.5 \pm 7.2$ & $16.7 \pm 7.6$ & $17.9 \pm 9.9$ & $18.8 \pm 8.4$ \\
$(\mathrm{~mL} / \mathrm{kg})$ & & & & & & \\
\hline
\end{tabular}

*normal volume fluid resuscitation; ${ }^{*}$ hypervolemia fluid resuscitation; ${ }^{Y_{30}}$ minutes after fluid resuscitation; ${ }^{i} 60$ minutes after fluid resuscitation; SVI: Stroke Volume Index; CI: Cardiac Index; SVRI: Systemic Vascular Resistance Index; MAP: Mean arterial pressure; $\mathrm{DO}_{2}$ : oxygen delivery; ELWI: Extravascular lung water Index

\section{Figures}


$\mathrm{ng} / \mathrm{L}$

110

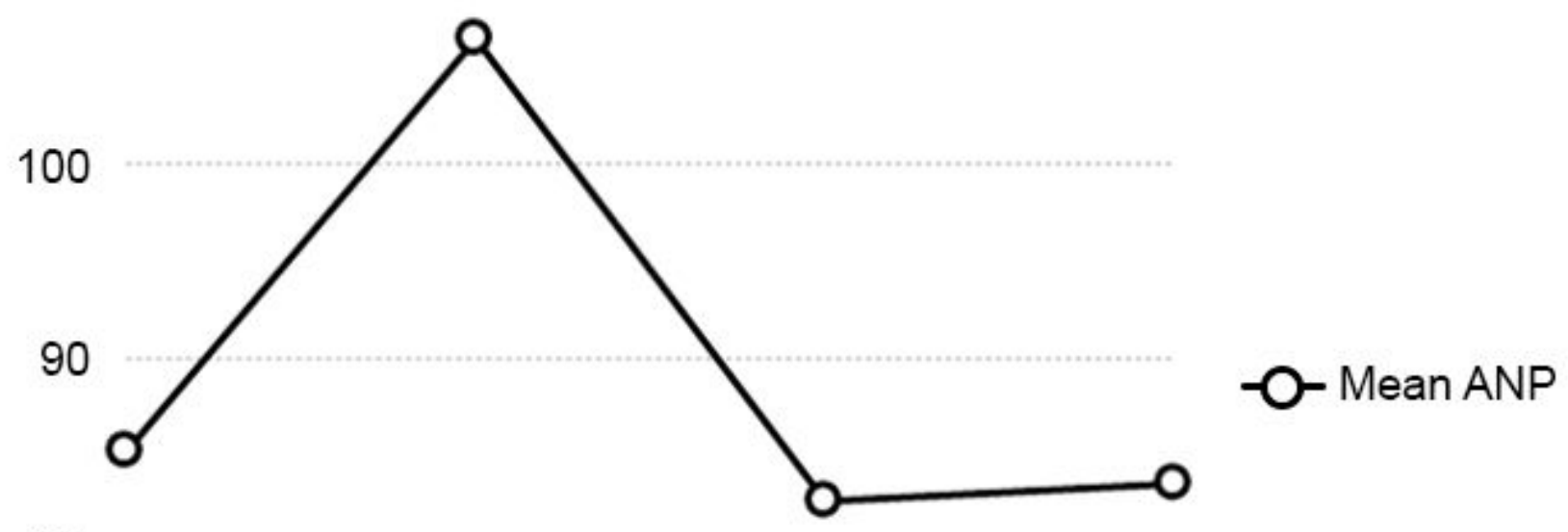

80

70

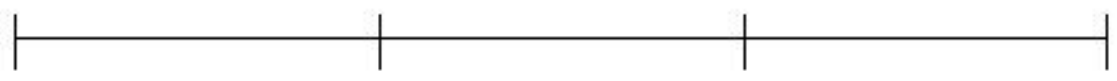

\section{Baseline $^{*} \quad$ Normal Volume $^{*}$ Hypervolemia 30 Minutes \\ Resuscitation Resuscitation After Resuscitation}

*paired t-test $p=0.043$

Figure 1

Serum ANP Levels. Mean serum ANP levels at baseline, after euvolemic resuscitation, after hypervolemic resuscitation and 30 minutes after fluid resuscitation. All data were normally distributed. 


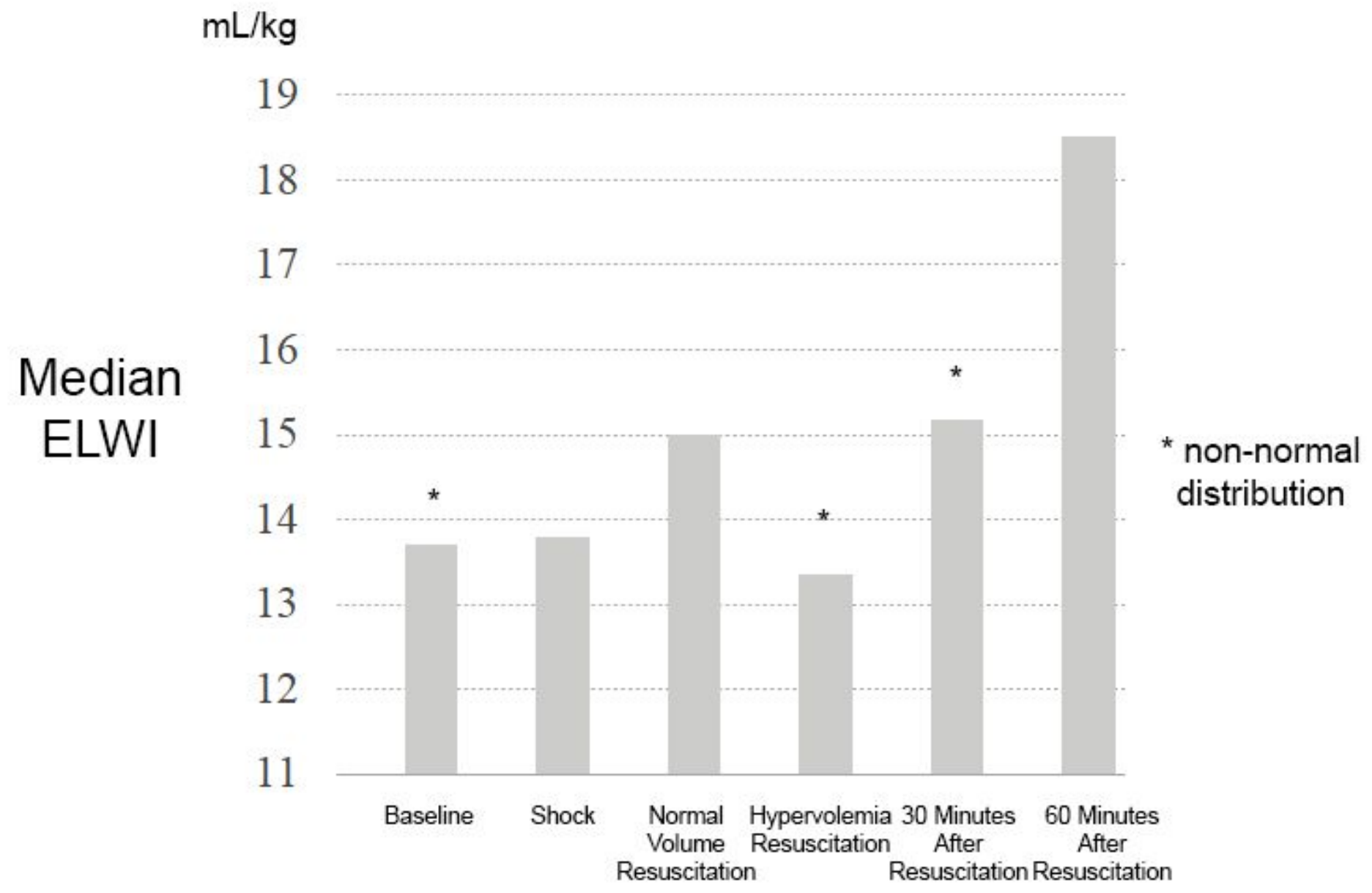

Figure 2

Median Extravascular Lung Water. Serial measurement of extravascular lung water at baseline, after induction of shock, after euvolemic resuscitation, following hypervolemic resuscitation, 30 minutes after fluid resuscitation, and 60 minutes after fluid resuscitation. * = Nonparametric data. 


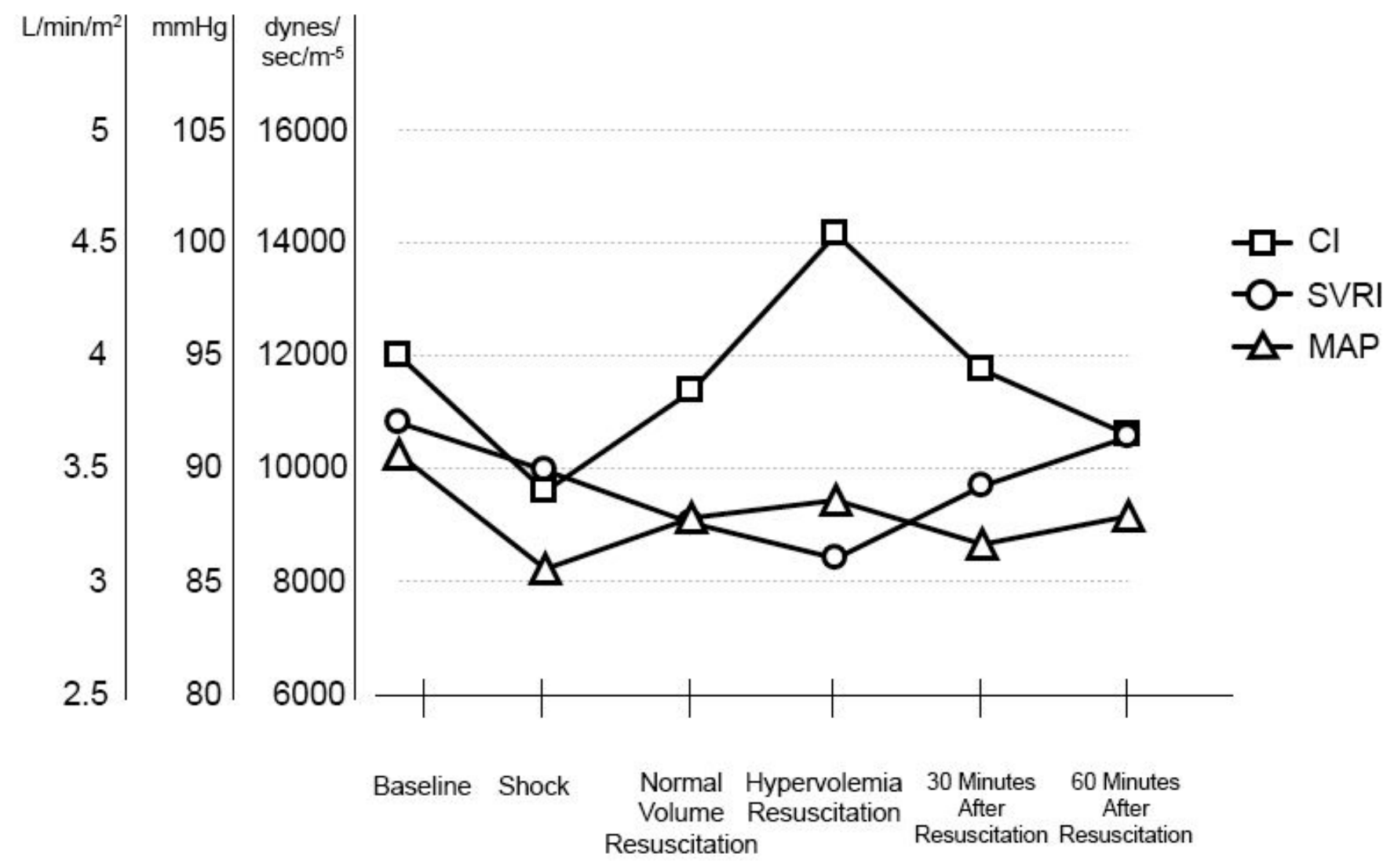

Figure 3

Systemic Vascular Resistance Index and Cardiac Index. Serial measurements of $\mathrm{Cl}$, SVRI, and MAP at baseline, shock, after euvolemic resuscitation, hypervolemic resuscitation, 30 minutes after fluid resuscitation, and 60 minutes after fluid resuscitation. SVRI decrease whilst $\mathrm{Cl}$ increases resulting in a stable MAP. All data are normally distributed. $\mathrm{Cl}=$ cardiac index; SVRI=systemic vascular resistance index; MAP=mean arterial pressure. 


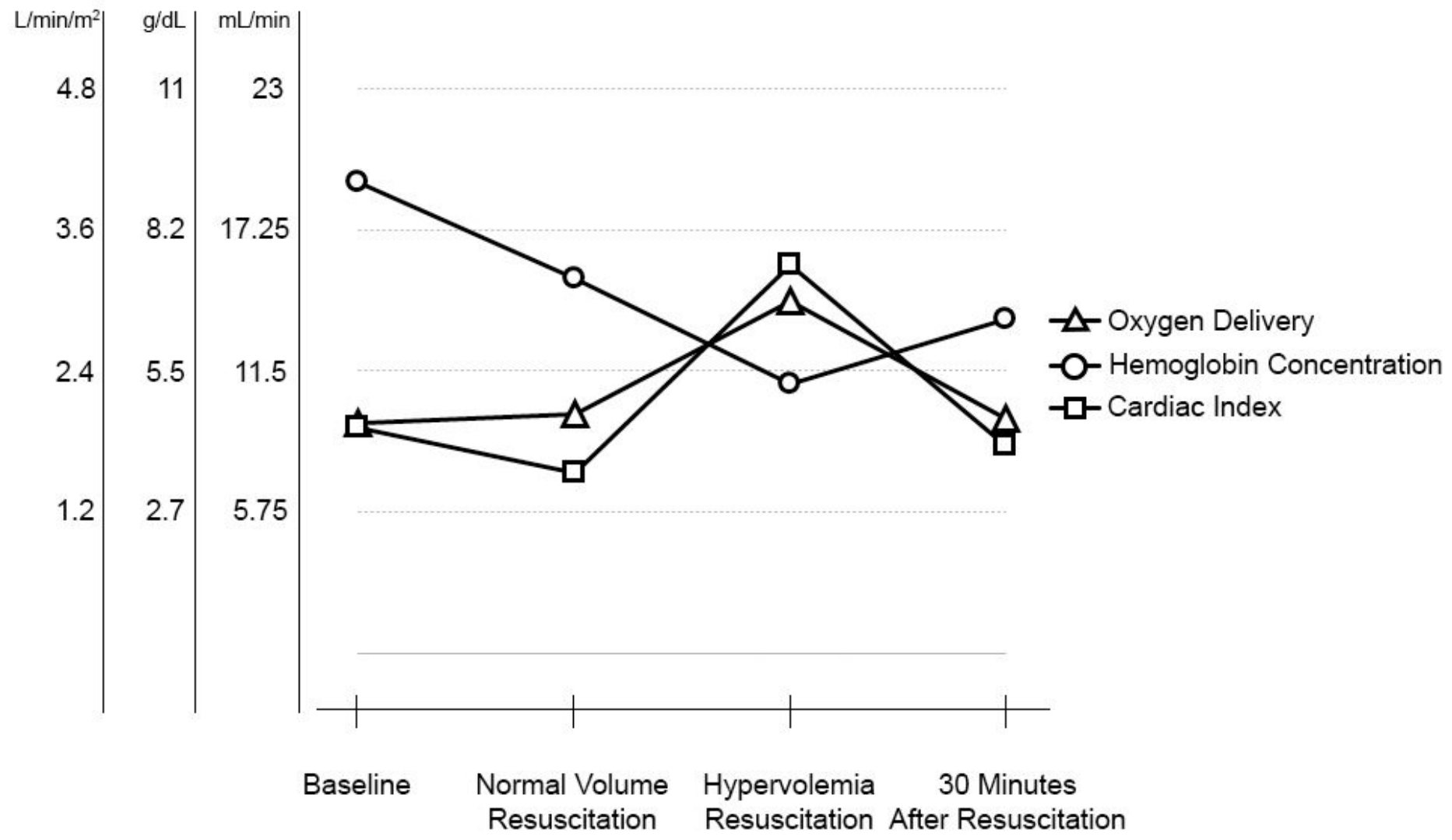

Figure 4

Increasing Cardiac Index and Oxygen Delivery After Fluid Resuscitation. Serial measurement of hemoglobin concentration, cardiac index and oxygen delivery at baseline, after euvolemic resuscitation, after hypervolemic resuscitation, and 30 minutes after fluid resuscitation. Although hemoglobin concentration decreases a proportionately greater increase of cardiac index results in an increased oxygen delivery. All data are normally distributed. 